\title{
Role of Science, technology and innovation for responding to Covid-19
}

\author{
Amrita Panja', Sujata Maiti Choudhury ${ }^{2}$ \\ ${ }^{1}$ Postdoc Fellow, ${ }^{2}$ Professor, Department of Human Physiology, Vidyasagar University, Midnapore, West Bengal, India
}

The sudden outbreak of severe acute respiratory syndrome coronavirus 2 (SARS-CoV-2) in the year 2020, has had an impact on different fields of the human life including health sciences, economics, societies and international relations. Science and technology play a crucial role in fighting this 'war without smoke'. The enormous power of science to manage the critical situation, arises during a pandemic and reminds us that by promoting scientific cultures we can overcome the situation. We must have faith on science in high regard. Although technology will not be able to restrict the onset of a pandemic; nevertheless, it can assist in dealing the emergency more effectively. During this time of sheer uncertainty and constant anxiety, our preparedness to adopt technology has been our lifeline. Certain applications of innovative approach of science and technology include distance learning, contact tracing applications, contactless online deliveries, dissemination of information, technology- based health services. Covid-19 has proved that technology innovations have been assisting in managing the epidemic in a timely, systematic, and peaceful manner. A moral learnt from the Covid-19 pandemic has been to stay well prepared in advance against any crisis at both an individual and national level. Progression in technology is steadily advancing; it will unquestionably continue to grow exponentially. We have to adapt changes in technology faster and continue to invest in building the technology systems for better awareness.

Key words: Science and technology; Covid-19; Cultures; Pandemic

\section{Access this article online}

Website:

http://nepjol.info/index.php/AJMS DOI: $10.3126 /$ ajms.v13i3.41543

E-ISSN: 2091-0576

P-ISSN: $2467-9100$

Copyright (c) 2022 Asian Journal of Medical Sciences

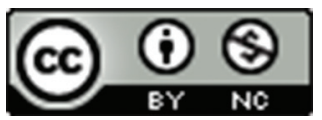

This work is licensed under a Creative Commons Attribution-NonCommercial 4.0 International License.

\section{INTRODUCTION}

"A strange darkness has come upon the world today. They who are most blind now see...

----Jibanananda Das

Over the last one year, the mankind has been tripped into one of its greatest crises. The crisis is striking hard on every field of human life including income, health and education. 'Coronavirus disease 2019 (Covid-19) pandemic is superimposed on unsolved tensions between people and technology, between people and the earth, between the haves and the have-nots.

Covid-19 first found in Wuhan China and gradually it has been distributed throughout the world at an alarming rate. It is recognised as pandemic in the world declared by the World Health Organization on 11 March $2020^{[1]}$. Covid-19 is caused by infection with Severe Acute Respiratory Syndrome Corona Virus 2 (SARSCoV-2). Covid-19 has devastating effects on people in all countries ${ }^{[2]}$. Since $2019 \mathrm{n}$-CoV disrupts and damages the human immune system, causing varying degrees of damage to different organs throughout the body. The number of confirmed cases of Covid-19 has already exceeded 209876613 and 4400284 deaths occurred worldwide on 20 ${ }^{\text {th }}$ August, 2021 08:52 pm GMT, according to $\mathrm{WHO}^{[3]}$. Therefore, there is an urgent need to treat the infected patient and reduce mortality.

Since the Second World War, Covid-19 pandemic postures a global health threat and leads to severe economic 
crisis ${ }^{[4]}$. The pandemic and the associated health hazards resulted in extensive and unprecedented social commotion ${ }^{[5]}$. The collective trauma has resulted in closure of educational institution, scarcity in businesses, increasing unemployment and a spike in emotional distress resulting from the pandemic and related secondary stressors. As per Government order, children are now accustomed in online learning process and non-essential businesses are either closed or employees are suggested to do work from home ${ }^{[6]}$. As the preventive management, extensive lockdown and maintenance of social distancing imposes high socio-economic cost [7]. Consequently, during this traumatic situation, we have seen a substantial rise in the use of science and technology, which is already integrated into the core of modern life during the pandemic era. People are now spending even more time with technology while overriding news media, watching television, using social media to communicate with others, utilizing lifestyle apps to shop for groceries and other consumer goods, and engaging in home workouts ${ }^{[8]}$. In addition, increased involvement in technology is obligatory of students for educational purposes and for those now working from home ${ }^{[9]}$. Much devotion has been directed at science, technology and innovation (STI) to provide solutions instantly.

The Covid-19 is probably going to alter our lives for many years to come. The socio-economic and emotional burden of this pandemic will no longer be the similar like before. Presently, most people are undergoing the restrictions of the lockdown, parting them to their fears, insecurity and separation. On the other hand, due to the unexpected 'extra time' there was space for new experiences and for personal reflections on what is indispensable in life, to observe nature and relations more consciously. Public health research should be transformed and prioritised, in order to take its role in the responsible steering of the society, post-Covid-19, to a new form of collaborative engagement approach to research.

The main objective of the present review study is to enlighten the state of STI during the pandemic situation. It first presents how the STI system helps in finding possible solution towards Covid-19 health hazard. Moreover, it further helps to decipher the major challenges which the global economy is facing during the pandemic situation. Science and technology have contributed a lot for providing solutions and to overcome the critical condition due to 'social distancing' maintenance during covid-19 by improving digital tools. Digital techniques proved essential to cope up the problems raised by social distancing and prolonged lock down, prevailed throughout the country during the pandemic.
Changes in different aspects of our life during the Covid-19

\section{Behavioural alteration}

Increased incidence of psychological burden appears after being quarantined for a prolonged time and it is more painful than physical sufferings caused by the virus. Children are more vulnerable than the people of other age groups in the society. Closure of educational institutions, lack of outdoor activity, aberrant dietary and sleeping habits are likely to interrupt children's usual lifestyle and can possibly trigger boredom, sorrow, impatience, aggravation and varied neuropsychiatric manifestations ${ }^{[10]}$. The negative effect of lifestyle related behaviours might cause mood swing which can lead to higher incidence of weight gain and associated metabolic complications during the pandemic condition. To maintain health during the Covid-19 pandemic, physical activity and nutritional supplementations are strongly suggested ${ }^{[11]}$. Individuals with obesity and metabolic comorbidities such as diabetes and cardiometabolic disease are more susceptible after getting Covid-19 infection ${ }^{[12,13]}$. Therefore, negative lifestyle related behaviours should be avoided as it can become a crucial hindering step in combating the disease. ${ }^{[14]}$ The improvement in dietary behaviour may lead to a positive approach towards calorie balance. Incidences of domestic violence, child abuse, cyber crimes are on the upsurge during the pandemic ${ }^{[15]}$.

\section{Research and innovation systems have responded extraordinarily to the pandemic}

Many researchers have shifted their research activities to dry-lab-based work that can be directed from home ${ }^{[16]}$. An international survey- based analysis reported that nearly half of the wet lab- based research activity converted into dry lab- based assay focussing more on writing, analysis, publishing research articles and planning for future research during the first wave of the lockdown ${ }^{[17]}$. Many institutes are utilizing their infra-structural facilities towards serving Covid-19 testing and related research works ${ }^{[18,19]}$. Due to lockdown phase prevailed during the pandemic situation, mobility of human resources has been severely interrupted. During the first months of the pandemic, many scientific events, seminars, conferences were cancelled. As the alternative procedure, many conferences and events are increasingly organised digitally and virtual presentations are preferred [20]. It gives an opportunity to reach more diverse audiences, as well as it reduces economic burden of organized events and also the carbon footprint of travel. However, virtual exchanges are not so efficient like inperson conferences. The pandemic situation often helps in building national and international research collaborations and is used to maintain long-term trusted relationships, as well as gives an opportunity for early-career researchers to find jobs and enhance the visibility of their work. 


\section{Patterns of collaboration in scientific field during the Covid-19 outbreak}

With advances in the field of technology, scientific collaborations can easily flow across state and country sides. There are some general technological approaches for communication, such as Zoom, Webex, or Microsoft Team meetings; emails; google meet, cloud-computing shared spaces; and other digital formats ${ }^{[21]}$. Although there are some collaborative research projects which cannot be conducted by virtual meetings and instead require face- to- face interaction. Majority of fieldwork, experimental or wet-lab researches cannot be accomplished over an internet connection. Under this pandemic situation, some survey- and wet-lab-based scientific collaborations have been decelerated or postponed ${ }^{[22]}$. Constrains and hurdles used to delay the time- sensitive laboratory projects and generally hinder the release of project funding and grants. In addition, laboratories have to adapt safety measures and adjust to work hard with less interpersonal interactions due to social distancing ${ }^{[23]}$. Many regular scientific activities directly have been shifted towards specific researches those combating Covid-19 ${ }^{[24]}$. Scientists belonging to life science and technology fields, support the virologists, epidemiologists, and health care workers by supplying protective equipments and IT infrastructure.

\section{Negative impacts on newcomer and female researchers}

The crisis generated by Covid-19 generally has low impact on well-known researchers, but have created a challenge to the early-career researchers and female researchers to maintain their positions in their respective fields. Women were also particularly suffered, as they have to spend more time on childcare and elderly care during the lockdown period ${ }^{[25]}$. Previous registered reports finds that women's research production significantly declined in March and April 2020 compared to earlier years, with a disproportionate impact on early-career researchers ${ }^{[26]}$.

In the home, women perform the bulk of care work, which is generally unpaid and imperceptible. Genderbased violence is increasing exponentially during the covid era. Many women are being forced to 'lockdown' at home whereas the services to support survivors are being interrupted or made inaccessible ${ }^{[27]}$. All over the world, women represent nearly 70 percent of the health workforce and are more likely to be front-line health workers, especially nurses, midwives and community health workers ${ }^{28]}$. They also represent as health facility service staff including cleaners, laundry, catering and like the same who are more likely to be exposed to the virus. General awareness and consciousness should be generated to protect girls and women from social violence. Health care response must be facilitated for the development of suffered women and and girls. Online services should be commenced on support and stand by the victims.

\section{Innovative companies were hit by lockdowns}

Many innovative businesses scaled back during the lockdown phase. According to a survey on innovative companies conducted by the German Federal Ministry for Economic Affairs and Energy, which revealed nearly $>50 \%$ of companies had suspended ongoing research and innovation projects, and $>20 \%$ were deciding to dismiss one or more projects. It has been estimated that many technology firms would not able to maintain operations for more than six months ${ }^{[29]}$.

\section{Business}

Indoor dining in restaurants may not be returned to pre-crisis levels for months - or possibly even years after the pandemic. The situation can be overcome by re-arranging menus and pricing. Special offers in highmargin items such as appetizers, desserts and beverages can be a mode of solution in this critical situation. Bank business is also influenced by the pandemic. Small business is now operating using software, rather than having staff and lack of manpower can be a major cause of reduced productivity. Covid-19 has hugely accelerated the growth of digital healthcare. Numerous digital health apps have been generated to cope up the health hazards. Recently, systematic review have reported that 'telehealth' interventions including the telephone,web, video-conference, and television delivered to patients with diabetes, heart failure, irritable bowel syndrome, chronic obstructive pulmonary disease, have found promising results.

\section{Educational opportunities and e-conferences}

There has also been a varied impact of Covid-19 on the scientific activities while considering the mode of scientific communication, collaboration, and training. It has been estimated that nearly $30 \%$ of researchers have attended virtual conferences since the beginning of pandemic situation $^{[33]}$. Scientific meetings are now arranged as a form of e-conference. During the pandemic situation, many young scientists are now learning programming languages. Pandemic situation gives them an opportunity to develop skills upon both wet and dry data sciences ${ }^{[34]}$.

\section{The role of STI to provide health facilities in Covid-19}

The standard method for testing Covid-19 is the reverse real-time PCR assay. It is a time-constraining method that requires trained specialists that eventually puts a limit on the number of tests conducted. Moreover, by using lateral flow immunoassay (LFIA) technology, Covid-19 can be detected in human serum. After covid-19 infection, the level of IgG and IgM antibodies against SARS-CoV-2 can be detected 
in human blood and their level can give indication about the disease stage and progression ${ }^{[35]}$.

The number of Covid-19 patients is gradually increasing at an alarming rate which require efficient monitoring and surveillance system. Infrared thermometers can be used for primary identification of the infected persons in a crowded place. However, later on, it did not seem to be much efficient to check the spread of the infection ${ }^{[36]}$.

Smart thermometers are now used to collect, store and analysed critically the readings obtained from the Covidsuspected persons. These results are mostly linked to some mobile applications and it permits people to be aware regarding their covid status. These acquired data also helps in producing maps on daily basis presenting regions facing an increase in high fevers in order to allow the administrative persons to locate potential hotspots.

Apart from that, Drones, robots, Internet of Medical Things (IoMT), global positioning system (GPS), and autonomous vehicles (AVs) technology not only confirm minimum human interaction but also can be beneficial to access infectious Covid-19 patients. Wearables, Bluetooth and GPS technology, help to regulate individual's health and their day to-day stress levels in remoteness. Altogether, these technologies can help researches and use of Artificial Intelligence (AI) can help to mitigate pandemics to reveal the new paradigm of Tele Medicine. All these applications of technology either can prevent the disease severity or helps in monitoring of the masses, paramedical staffs, symptomatic, and asymptomatic Covid positives during the pandemic.

Vaccination to combat with the pandemic situation Hopes for recovery from Covid -19 with full swing vaccination drive are increasing more, but to irradicate the disease are yet now on front of a great challenge fully. There are several safe and effective vaccines that prevent people from getting seriously ill or dying from covid-19. Being vaccinated does not mean that we can throw caution to the wind and put ourselves and others at risk, particularly because research is still ongoing into how much vaccines protect not only against disease but also against infection and transmission (https://www.who.int/emergencies/ diseases/novel-coronavirus-2019/covid-19-vaccines) This is one part of managing Covid-19. In addition to the main preventive measures, we have to stay at least one metre away from others, have to cover our sneezing by elbow, frequently cleaning hands, wearing a mask and avoiding poorly ventilated rooms or opening a window.

\section{Future scenario for Covid-19}

The decisions of global corporations and governments, most importantly the behaviours of citizens in every society, will greatly influence the journey ahead. There are many possible outcomes. At one extreme is the most bright and positive scenario, in which new-generation Covid-19 vaccines are effective against all variants of SARS-CoV-2 (including those that may yet emerge in forecoming days) and viral control is tracked effectively in every country in a coordinated effort to achieve global control ${ }^{[37]}$.

The International Science Council(ISC) which is known as the independent global voice for science in the broadest sense, advisees us to select correct measurements by using STI to cope up with the mid-term(first 2-3 month from the detection of Covid-19) and long-term problems found during Covid-19. At the other extreme is a negative scenario, in which SARS-CoV-2 variants emerge repeatedly with the ability to seepage vaccine immunity, so that only high-income countries can respond by rapidly manufacturing adapted vaccines for multiple rounds of population reimmunization in pursuit of national control while the rest of the world struggles with repeated waves and vaccines that are not sufficiently effective against newly circulating viral variants ${ }^{[38]}$.

\section{SUMMARY}

Covid-19 had considerable effects on science and technology, causing stress and work interruptions, but at the same time new patterns of local and international cooperation, innovative idea exchange, and electronic learning procedures prominently appearing. Some of these new practices might be helpful for returning back the 'business as usual' in the future. The capability to work efficiently from home, and to collaborate productively with scientists and clinicians without extensive travel (and the associated carbon footprint) can enlighten the ray of hope towards the benefits for scientific communities and society as a whole.

While we deal with the crisis, we must use the prospect to recover better and build sustainable societies. This crisis requires all of us to make hard choices. These choices will be easier if we make them together. During the Covid-19 pandemic, the society's reliability on technology is gradually increasing as the social and occupational changes occur that may persist even long after the current crisis declines. Therefore, it is authoritative to make mindful and intentional choices about how to control the power of technology to improve our lives by reducing stress and to improve mental health. Most importantly, individuals should limit repeated exposure to media coverage of the pandemic and other painful social proceedings and should try to evade their work burden ${ }^{[39-41]}$. 
In conclusion, the current Covid-19 crisis provides prospects for clinicians, researchers, employers, politicians, and general people to explore best practices towards the mindful use of science and technology to reduce the harmful effects of stress and improve people's living status.

\section{REFERENCES}

1. Cucinotta D, Vanelli M. WHO Declares COVID-19 a Pandemic. Acta Biomed. 2020;91(1):157-160. doi: 10.23750/abm. v9111.9397.

2. Cascella M, Rajnik M, Aleem A, Dulebohn SC, Di Napoli R. Features, Evaluation, and Treatment of Coronavirus (COVID-19). 2021 Jul 30. In: StatPearls [Internet]. Treasure Island (FL): StatPearls. PMID: 32150360

3. https://www.who.int/emergencies/diseases/novel-coronavirus-2019 (accessed on 21 August 2021).

4. Mallah SI, Ghorab OK, Al-Salmi S, Abdellatif OS, Tharmaratnam T, Iskandar MA, Sefen JAN, Sidhu P, Atallah B, El-Lababidi R, Al-Qahtani M. COVID-19: breaking down a global health crisis. Ann Clin Microbiol Antimicrob. 2021;20(1):35. doi: 10.1186/s12941-021-00438-7.

5. Nicola M, Alsafi Z, Sohrabi C, et al. The socio-economic implications of the coronavirus pandemic (COVID-19): A review. Int J Surg. 2020;78:185-193. doi:10.1016/j. ijsu.2020.04.018.

6. Ahmed SA, Hegazy NN, Abdel Malak HW, Cliff Kayser W $3^{\text {rd }}$, Elrafie NM, Hassanien M, Al-Hayani AA, El Saadany SA, AiYoubi $\mathrm{AO}$, Shehata $\mathrm{MH}$. Model for utilizing distance learning post COVID-19 using (PACT) ${ }^{\mathrm{TM}}$ a cross sectional qualitative study. BMC Med Educ. 2020;20(1):400. doi: 10.1186/s12909020-02311-1.

7. Marston HR, Ivan L, Fernández-Ardèvol $M$, Rosales Climent A, Gómez-León M, Blanche-T D, Earle S, Ko PC, Colas S, Bilir B, Öztürk Çalikoglu H, Arslan H, Kanozia R, Kriebernegg U, Großschädl F, Reer F, Quandt T, Buttigieg SC, Silva PA, Gallistl V, Rohner R. COVID-19: Technology, Social Connections, Loneliness, and Leisure Activities: An International Study Protocol. Front Sociol. 2020;5:574811. doi: 10.3389/ fsoc. 2020.574811.

8. Garfin DR. Technology as a coping tool during the coronavirus disease 2019 (COVID-19) pandemic: Implications and recommendations. Stress Health. 2020;36(4):555-559. doi:10.1002/smi.2975

9. Lai CC, Shih TP, Ko WC, Tang HJ, Hsueh PR. Severe acute respiratory syndrome coronavirus 2 (SARS-CoV-2) and coronavirus disease-2019 (COVID-19): The epidemic and the challenges. Int J Antimicrob Agents. 2020;55(3):105924. doi: 10.1016/j.jjantimicag.2020.105924.

10. Ghosh R, Dubey MJ, Chatterjee S, Dubey S. Impact of COVID -19 on children: special focus on the psychosocial aspect. Minerva Pediatr. 2020;72(3):226-235. doi: 10.23736/ S0026-4946.20.05887-9.

11. Ghosh A, Arora B, Gupta R, Anoop S, Misra A. Effects of nationwide lockdown during COVID-19 epidemic on lifestyle and other medical issues of patients with type 2 diabetes in north India. Diabetes Metab Syndr. 2020;14(5):917-920. doi: 10.1016/j.dsx.2020.05.044.

12. Chopra S, Ranjan P, Singh V, Kumar S, Arora M, Hasan MS, Kasiraj R, Suryansh, Kaur D, Vikram NK, Malhotra A, Kumari A, Klanidhi KB, Baitha U. Impact of COVID-19 on lifestyle-related behaviours- a cross-sectional audit of responses from nine hundred and ninety-five participants from India. Diabetes Metab Syndr. 2020;14(6):2021-2030. doi: 10.1016/j.dsx.2020.09.034.
13. Ranjan P, Kumar A, Chowdhury S, Pandey S, Choudhary A, Bhattacharya A, Singh A, Pandey RM, Wig N, Vikram NK. Is excess weight a risk factor for the development of COVID 19 infection? A preliminary report from India. Diabetes Metab Syndr. 2020;14(6):1805-1807. doi: 10.1016/j.dsx.2020.09.012.

14. Pietrobelli A, Pecoraro L, Ferruzzi A, Heo M, Faith M, Zoller T, Antoniazzi F, Piacentini G, Fearnbach SN, Heymsfield SB. Effects of COVID-19 Lockdown on Lifestyle Behaviors in Children with Obesity Living in Verona, Italy: A Longitudinal Study. Obesity (Silver Spring). 2020;28(8):1382-1385. doi: 10.1002/oby.22861.

15. Sifat RI. Impact of the COVID-19 pandemic on domestic violence in Bangladesh. Asian J Psychiatr. 2020;53:102393. doi:10.1016/j.ajp.2020.102393

16. Stenvot L. (2020), "CNRS Labs: Research Under Lockdown", CNRS News, https://news.cnrs.fr/articles/cnrs-labsresearch-under-lockdown (accessed on 18 May 2020).

17. Baynes G, Hahnel M. Springer Nature. 2020.Research Practices in the wake of COVID-19: Busting open the myths around open data. https://www.springernature.com/gp/advancingdiscovery/blog/blogposts/research-practices-in-the-wake-ofcovid/18256280 (accessed on 22 August 2021).

18. Viglione $\mathrm{G}$. Tens of thousands of scientists are redeploying to fight coronavirus. Nature. 2020 27. doi: 10.1038/d41586-02000905-9.

19. Baker N. These cancer scientists turned their lab into a coronavirus-testing facility. Nature. 2020;580(7804):441. doi: 10.1038/d41586-020-01109-x.

20. Castelvecchi D. 'Loving the minimal FOMO': First major physics conference to go virtual sees record attendance. Nature. 2020;580(7805):574. doi: 10.1038/d41586-020-01239-2.

21. Clark TR. Harvard Business Review. 2020. "8 Ways to Manage Your Team While Social Distancing." https://hbr.org/2020 103/8-ways-to-manage-your-team-while-social-distancing (accessed on 24 March 2020).

22. Radecki J, Schonfeld RC. The Impacts of COVID-19 on the Research Enterprise: A Landscape Review (Research Report). New York: ITHAKA S+R; 2020. doi.org/10.18665/ sr.214247.

23. Brockmeier EK. Penn Today. University of Pennsylvania; 2020. [June 8, 2020]. Research returns to campus. https://penntoday . upenn.edu/news/phase-i-research-resumption.

24. Korbel JO, Stegle O. Effects of the COVID-19 pandemic on life scientists. Genome Biol. 2020;21(1):113. doi: 10.1186/s13059020-02031-1.

25. Ali $R$, Ullah $H$. Lived experiences of women academics during the COVID-19 pandemic in Pakistan. Asian J Soc Sci. 2021;49(3):145-152. doi:10.1016/j.ajss.2021.03.003.

26. Vincent-Lamarre $P, C$. Sugimoto, V. Larivière. The decline of women's research production during the coronavirus

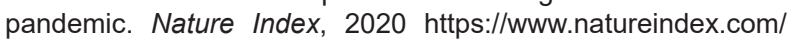
news-blog/decline-women-scientist-research-publishingproduction-coronavirus-pandemic

27. Mittal S, Singh T. Gender-Based Violence During COVID-19 Pandemic: A Mini-Review. Front Glob Womens Health. 2020 8;1:4. doi: 10.3389/fgwh.2020.00004.

28. Boniol M, Mclsaac M, Xu L, Wuliji T, Diallo K, Campbell J. Gender equity in the health workforce: analysis of 104 countries. Working paper 1. Geneva: World Health Organization; 2019 (WHO/HIS/HWF/Gender/WP1/2019.1).Licence: CC BY-NC-SA 3.0 IGO.

29. Solomon S. (2020), "Most early stage Israeli startups at risk of closure due to pandemic - survey", The Times of Israel, https://www. timesofisrael.com/early-stage-israeli-startups-at-risk-of-closuredue-to-pandemic-survey-shows (accessed on 2 June 2020).

30. Sijbrandij M, Kunovski I, Cuijpers P. Effectiveness of internet- 
delivered cognitive behavioral therapy for posttraumatic stress disorder: a systematic review and meta-analysis. Depress Anxiety. 2016;33(9):783-91. doi: 10.1002/da.22533.

31. Lawes-Wickwar S, McBain H, Mulligan K. Application and Effectiveness of Telehealth to Support Severe Mental Illness Management: Systematic Review. JMIR Ment Health. 2018;5(4):e62. doi: 10.2196/mental.8816.

32. Rush KL, Hatt L, Janke R, Burton L, Ferrier M, Tetrault M The efficacy of telehealth delivered educational approaches for patients with chronic diseases: A systematic review. Patient Educ Couns. 2018;101(8):1310-1321. doi: 10.1016/j. pec.2018.02.006.

33. Muthuprasad T, Aiswarya S, Aditya KS, Jha GK. Students' perception and preference for online education in India during COVID -19 pandemic. Soc Sci Humanit Open. 2021;3(1):100101. doi: 10.1016/j.ssaho.2020.100101.

34. Zalat MM, Hamed MS, Bolbol SA. The experiences, challenges, and acceptance of e-learning as a tool for teaching during the COVID-19 pandemic among university medical staff. PLoS One. 2021;16(3):e0248758. doi: 10.1371/journal.pone.0248758.

35. Yang T, Gentile M, Shen CF, Cheng CM. Combining point-ofcare diagnostics and internet of medical things (loMT) to combat the COVID-19 pandemic, Diagnostics (Basel). 2020; 10 (4):224.
36. Peprah K, Topfer LA. Infrared TemperatureDevices for Infectious Disease Screening During Outbreaks: Overview of an ECRI Evidence Assessment. Ottawa: CADTH;2020 May. (CADTH technology review: focused critical appraisal; no.30).

37. Aravindakshan A, Boehnke J, Gholami E, NayakA. Preparing for a future COVID-19 wave: insights and limitations from a data-driven evaluation of non-pharmaceutical interventions in Germany. Sci Rep. 2020;10(1):20084. doi: 10.1038/s41598-020-76244-6.

38. Skegg D, Gluckman P, Boulton G, Hackmann H, Karim SSA, Piot P, Woopen C. Future scenarios for the COVID-19 pandemic. Lancet. 2021;397(10276):777-778. doi: 10.1016/ S0140-6736(21)00424-4.

39. Turel O, Serenko A, Bontis N. Family and work-related consequences of addiction to organizational pervasive technologies. Information \& Management. 2021; 48(2-3), 88-95. doi.org/10.1016/j.im. 2011.01.004

40. Haidt J, Allen N. Scrutinizing the effects of digital technology on mental health. Nature. 2020;578(7794):226-227. doi: 10.1038/ d41586-020-00296-x.

41. Chao M, Xue D, Liu T, Yang $H$, Hall BJ. Media use and acute psychological outcomes during COVID-19 outbreak in China. J Anxiety Disord. 2020;74:102248. doi: 10.1016/j. janxdis.2020.102248.

\section{Authors Contribution:}

AP- designed the proposal, performed and analysed the topic. SMC- designed and critically revised the article. Both the authors participated sufficiently in the study to take responsibility for designing, analysis, writing or revision of the manuscript.

\section{Work attributed to:}

Department of Human Physiology, Vidyasagar University, Midnapore, West Bengal, India, Pin: 721102

Orcid ID:

Amrita Panja - (1) https://orcid.org/0000-0002-2857-1062

Sujata Maiti Choudhury - https://orcid.org/0000-0002-5239-1352

Source of Support: Nil, Conflict of Interest: None declared. 